\title{
Effects of Technology Context on Cloud Computing Adoption in Small and Medium Enterprises in Nairobi County, Kenya
}

\author{
Emily Mworia Chemjor ${ }^{1}$, Charles Lagat ${ }^{2}$ and Loice Maru ${ }^{3}$ \\ ${ }^{1}$ PhD Candidate, Department of Management Science, School of Business and Economics, Moi University, P. O. Box \\ 3900-30100, Kenya; \\ ${ }^{2}$ Senior Lecturer, Department of Marketing Management, School of Business and Economics, Moi University, P. O. \\ Box 3900-30100, Kenya; \\ ${ }^{3}$ Professor of Entrepreneurship and Sustainability Management, Department of Management Science, School of \\ Business and Economics, Moi University, P.O. Box 63056 - 00200, Nairobi, Kenya.
}

\begin{abstract}
For most developing nations, Small and Medium Enterprises (SMEs) play a vital role in the quest to militate against the vagaries of poverty and stimulate growth and development. However SMEs continue to face a number of challenges as a result of stiff competition and rapid evolvement in the contemporary business market. Against a background of stiff competition and turbulent business environments, ICT solutions have the ability to enhance SMEs competitiveness leading to efficiency and effectiveness for business sustainability. This study sought to investigate the effects of technology context on cloud computing adoption in SMEs in Nairobi County, Kenya. The study employed a positivism approach and utilized an explanatory research design using the Innovation Diffusion Theory as a theoretical basis. The study sample comprised 398 respondents drawn from Nairobi County. Data that was collected through pre-tested structured questionnaires and analyzed using descriptive and inferential statistics and multiple regression analysis. Results from regression model showed that technological context exhibited a positive and significant effect on the level of adoption of cloud computing $(\beta 1=0.414, \rho<0.05)$. This study demonstrates that technology context and its attendant aspects (relative advantage, compatibility and complexity), significantly influence cloud computing adoption. The author recommend that stakeholders in the SMEs field should strive to ensure that their efforts to improve on cloud computing adoption are guided by the technological context of cloud computing.
\end{abstract}

Key Words: Technological Context, Relative Advantage, Compatibility, Complexity, Cloud Computing Adoption

\section{Introduction}

Small and Medium Enterprises (SMEs) are the silent drivers of a nation's economy. Researchers argue that SMEs play a major role in poverty alleviation in developing countries and also stimulate domestic and regional economic growth in national and regional economies [1,2]. They help to diversify economic activity and are flexible to changing market demands [3]. However, due to rapid evolvement in the contemporary business market, competition is stiff [4] leaving innovation as key for any business growth. Consequently, SMEs that wish to operate and survive in competitive markets have to resort to Information and Communication Technology (ICT) solutions which have the ability to enhance their competitiveness hence contribute towards efficiency and effectiveness for business sustainability. ICT empowers SMEs to compete with large firms [5, 6]. However, SMEs mainly use the traditional ICT solutions to stay competitive [6]. Traditional ICT leads to several challenges SMEs face, such as lack of capital, skilled staff and complex management.

SMEs must, therefore, be made more competitive, innovative to generate growth. Since SMEs play a role of increasing importance in the economy, especially when we consider their contribution to the generation of jobs as well as the social-economic growth of the public where they are located [7], it is then applicable that SMEs are stimulated into adopting new technologies and shaping competitive innovative products and services.

Small Medium Enterprises have the right environment to prosper, from a skilled work force and drive economic growth. In particular, small and medium sized companies (SMEs) will be able to seize this opportunity in a wide variety of ways and small entrepreneurs have a critical role to play. It is noteworthy that inasmuch as SMEs play a vital role in the economy by nurturing competitiveness and employment, they are often faced with problems in attaining capital for the early start-up stages due to their small size $[8,9,10]$ which may restrict their access to new technologies or innovations.

Cloud computing is a new paradigm shift in which including computing resource services, soft applications of distributed systems and data storage computing world is quickly transforming toward a system of deriving relative applications for millions to extend as a service rather than to run on their personal computers[11, 12]. Computing is a massively scalable IT-related capabilities provided as a service to external customers using internet technologies [13]. 
Erdogmus [14] considers cloud computing a pool of highly scalable abstracted infrastructure capable of hosting end-customer applications that are billed by consumption. IT capabilities are referred to as real time over the Internet services provisioned, delivered, and consumed on request [15]. Besides, cloud computing is an enclosed business model about new technologies, such as virtualization, applications (Software as a Service (SaaS), platform (Platform as a Service (PaaS), and hardware (Infrastructure as a Service (IaaS) [16].

To realize business agility to enhance competitiveness, SMEs need to streamline output to reasonable costs, improve on process innovation and assimilate new technologies. IT departments are persistently under pressure to offer new solutions that are considered more flexible, efficient and cost-effective, enabling even faster time to market. A flexible IT infrastructure can remove some of the barriers to global competition and allow smaller businesses to be efficient, allowing them to have a competitive edge hence providing a degree of flexibility. Cloud computing has the potential to play a major role in addressing inefficiencies and make a dynamic contribution to the growth and competitiveness of SMEs which are the pillar for economic growth and job creation[17]. By adopting cloud computing service models, SMEs will be able to avoid large up-front costs on IT resources for their production needs and business model of innovation [18, 19, 20, 21].

\section{Adoption of Cloud Computing}

While cognizant of the fact that the determinants of cloud computing adoption are distinguished into three setting groups: technological, organizational, and environmental [22], as classified under the TOE framework [23, 24, 25], this paper focuses on the technological context. For the purposes of this discussion, technological setting alludes to inner and outside innovations appropriate to the firm [26, 27]. In addition, we adopt Baker's[28]view that technological setting speaks to the inner and outer advancements identified within the firm; both advances that are as of now being used at the firm and in addition those that are accessible in the market yet not at present being used. These advancements may incorporate either equipment or practice. Technology context consists of three properties - relative advantage, compatibility and complexity.

Rogers [29] defines relative advantage as the degree to which an innovation is perceived as being better than the idea it superseded (other computing paradigms). Cloud computing has both technical and economic advantages over traditional IT environments. Rogers [30] characterizes relative favourable position as how much a technological variable is seen as giving more noteworthy advantage to firms. To and Ngai [31] note that it is sensible that organizations mull over the points of interest that originate from adopting innovations. Cloud computing services, which permit operations to be summed up and prepared through web exchanges, can substitute for or supplement ERP computer programs.

The normal advantages of inserted cloud computing services incorporate the accompanying: speed of business correspondences, productive coordination among firms, better client interchanges, and access to market data preparation [32]. Cloud computing has advantage over different innovations, for example, decreased cost, versatility, portability and shared assets. Feuerlicht and Govardhan [33] note that cloud computing offers leased services on pay-as-you-utilize premise which prompt to changing the level of utilization as necessitated by the needs of a firm. The likelihood of reception will increase when organizations see a relative preferred standpoint in an innovation $[34,35,36]$.

In this way, Sokolov [37] comments that relative focal points of cloud computing are shown even from ICT capability-ties viewpoint. In any case, Buyya et al. [38] point out that firms might not have trust in a cloud computing framework since it is generally new to them. It might require clients a long investment to comprehend and execute the new framework. Subsequently, many-sided quality of an innovation can go about as a hindrance to usage of new innovation; unpredictability component is typically adversely influenced [39].

Rogers [29] notes that compatibility alludes to how much innovation fits with the potential adopter's current qualities, past practices and current needs. Compatibility has been viewed as a fundamental component for adoption of innovation [40]. At the point when innovation is perceived as good with work application frameworks, firms are generally prone to consider the adoption of new innovation. At the point when innovation is seen as fundamentally contrary, significant modification in procedures that include impressive learning are required as the firms are most unlikely to adopt the technology. For SMEs, it is essential that the new innovation is consistent with their existing values and needs, since poor integration of new systems with existing ones could result in the opposite situation [41, 42, 43].

Complexity is the degree to which an innovation is perceived as relatively difficult to understand and use [29]. Parisot [44] and Sahin [45] have espoused that new technologies have to be user-friendly and easy to use in order to increase the adoption rate. At the point when SMEs are faced with difficulties regarding changing the procedures in which they cooperate with their business frameworks, then they are no doubt not to receive new innovation. Jain and Bhardwaj [46] note that portability offers clients the facility of getting to and working away at their records from anyplace on the planet; if they have access to a personal and a web connection. Jain and Bhardwaj (ibid) note that shared assets is another preferred standpoint to the organizations offered by cloud 
computing which empowers their workers. Figure 1 is a representation of how the technology context affects cloud computing adoption.

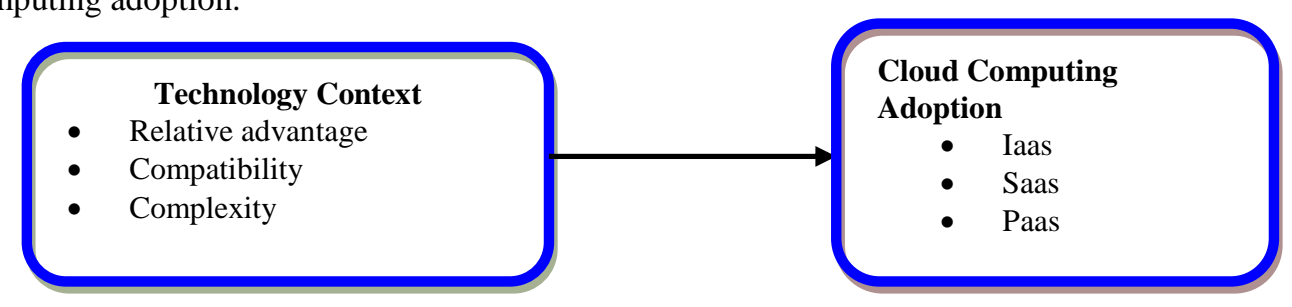

Figure 1: Effects of Technology Context on Cloud Computing Adoption

As earlier mentioned, SMEs are most likely to adopt a technology if they perceive the technology compatible with their existing work, not complex to use and has a relative advantage. However, studies on effect of technological context on cloud computing adoption are inconclusive. While some studies have found technology context useful in understanding critical factors of IT adoption in a given organisation [22], results have been varying depending on different scholars and environment [31, 40, 47]. Moreover, insignificant results on the effect of complexity and compatibility on cloud adoption was inconsistent with previous studies [40, 48] but consistent results with those of Lin and Lin [49].

In addition, while cloud computing has been discussed as a new technology development that can provide several advantages both strategic and operational to its adopters, the adoption rate is slower than anticipated [16]. For instance, in Kenya, despite the government efforts at increasing the competitiveness of SMEs through ICT by enhancing internet infrastructure and accessibility, the adoption of cloud computing among SMEs has not been satisfactory [50]. Kituku [51] has also observed that cloud computing is still new to both academia and commerce in Kenya. Despite the great advantage of cloud computing, many research discoveries are in the developed countries [52] and very few in the developing countries. As a result, the authors of this paper deemed it necessary to carry out a study that sought to address the research gap by analyzing the effect of technology context as a determinant of cloud computing adoption.

\section{Theoretical Underpinning}

The Innovation Diffusion Theory provided a theoretical basis for the study. The theory was developed by E.M. Rogers in 1962. Diffusion is the procedure by which a development is embraced by individuals from a specific group. Research on diffusion of innovation has been generally connected in sectors such as education, sociology, communication, agriculture, marketing and data innovation [53, 54). Rogers [53] notes that an innovation is a thought practice, or element that is seen as new by an individual or another unit of adoption. Rogers (ibid) also notes that diffusion is not a solitary, general hypothesis, yet rather a few hypothetical points of view that identify with the general idea of diffusion, that is, it is a meta-hypothesis. On the other hand, diffusion is the procedure by which an innovation is imparted through specific channels after some time among the individuals from a social framework (ibid). Accordingly, Agarwal [54] points out that the IDT hypothesis contends that potential clients settle on choices to receive or dismiss an innovation in view of convictions that they shape about the innovation. According to Rogers [53], four variables impact the reception of an innovation by individuals from an organization: (1) the innovation itself, (2) the correspondence channels used to spread data about the innovation, (3) time, and (4) the nature of the group to which it is presented. As indicated by Rogers (ibid), there are two noteworthy hypotheses that deal with the dissemination of innovation particularly for reasons for embracing ICT for organizations like SMEs. These are: (1) the individual innovativeness hypothesis, (2) the hypothesis of perceived properties. The Individual Innovativeness Theory depends on who embraces the innovation and when. With an innovator who is daring and pioneers driving the way, they can receive regardless of a high level of vulnerability about the innovation at the season of adoption, and will acknowledge an incidental difficulty when another thought demonstrates unsuccessful. Business visionaries and managers of SMEs constitute the adopters who at their own particular volition and relying upon the apparent expenses and benefits decide to adopt information and communication technology Diffusion hypothesis gives a structure that comprehends why ICT is received by a few people and not by others. This hypothesis can clarify, anticipate, and represent elements that expand or obstruct the dispersion of innovations. Reviews on ICT appropriation have by and large adopted three conceivable strategies: a diffusion approach, an adoption approach and a domestication approach [55]. Roger's Diffusion of Innovation hypothesis [45, 56] contends that media and interpersonal contacts give data that impacts an individual's supposition and judgment. The hypothesis involves four components: creation, diffusion through the informal organizations, time and results. Data channels through the systems and relying upon the way of the systems and the parts of its supposition pioneers, new innovations are either embraced or dismissed. Opinion leaders impact a group of people through 
individual contact while mediators, for example, change operators and guardians additionally add to the procedure of diffusion.

\section{Research Methodology}

This study employed a positivism approach and utilized an explanatory research design. The target population comprised of SMEs managers drawn from estimated 102,963 registered SMEs within Nairobi County [56]. All the SMEs that had not adopted cloud computing were excluded from the study population in light of cloud computing service provider, hence the review focused on 82,821 SMEs. A cluster-sampling technique was employed in selecting a sample from the target population [57]. By using the formula:

$$
n=\frac{N}{1+N e^{2}}
$$

Where: $\mathrm{n}=$ Sample size; $\mathrm{N}=$ Population size; $\mathrm{e}=$ the error of Sampling and on substitution with an error of sampling at 0.05 :

$$
n=\frac{82821}{1+82821\left(0.05^{2}\right)}=398 \text { employees, }
$$

the sample size was 398 SMEs as shown in Table 1.

Table 1: Sample Size

\begin{tabular}{|l|c|c|}
\hline \multicolumn{1}{|c|}{ Table 1: Sample S1ze } \\
\hline Industry & No of SMEs & Sample Size \\
\hline Manufacturing & 11392 & 55 \\
\hline Hospitality & 18759 & 90 \\
\hline Consulting & 9267 & 45 \\
\hline Information technology & 13157 & 63 \\
\hline Computer retail & 13627 & 65 \\
\hline Tours \& travel & 16619 & 80 \\
\hline Total & $\mathbf{8 2 8 2 1}$ & $\mathbf{3 9 8}$ \\
\hline
\end{tabular}

The study adopted primary data that was collected from IT managers, managers or entrepreneurs through pre-tested structured questionnaires. The independent variables were the components of technology context - relative advantage, complexity and compatibility - while the dependent variable was adoption of cloud computing by SMEs. The measurement tool of relative advantage preferred standpoint was embraced from Feuerlicht and Goverdhan [33] and Jain and Bhardwaj [46]. Complexity tool was adopted from Premkumar et al. [39] and Gardner and Amoroso [58]. Compatibility tool was adopted from Wang et al. [40]. Reviewed literature demonstrates constructs testing for reliability accomplished by ascertaining the Cronbach's alpha coefficient. Further, to accomplish construct validity, convergent and discriminant validity were set up. The relationship grid and between construct connection were examined for joined and discriminant validity. Information gathered on demographic variables was handled and detailed in percentage through descriptive analysis. The study employed inferential statistics in the form of multiple regression and Pearson correlations analyses. Regression was used to test the degree to which the independent variables predict the dependent variable and correlations was used to test for the statistical relationship between variables.

\section{Results}

As shown in Figure 2, 52.2\% (168) of the respondents were managers, 44.4\% (143) were IT managers and $3.4 \%$ (11) were owners. This distribution provided a diversified base of information given the contribution of the different responsibilities played by the respondents. In terms of the highest level of education, $69.6 \%$ (224) of the respondents had a degree, $24.8 \%$ (80) of them had a Diploma and 5.3\% (17) of them had a Masters degree. It is evident that the respondents possessed the requisite skills to perform their duties effectively. As such, the respondents' educational attainments were part of the organizations' human capital.

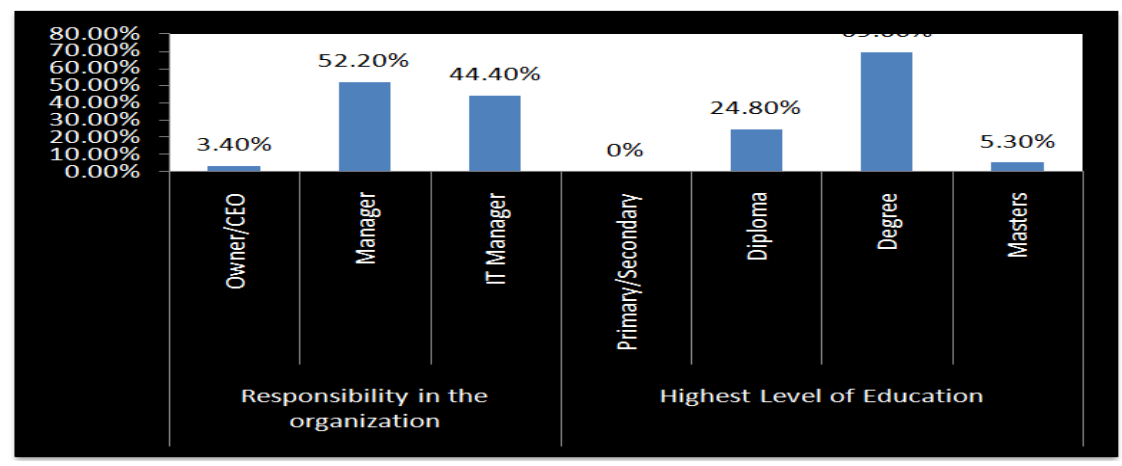

Figure 2: Respondents' Demographics 
In terms of the relative advantage of cloud computing, the respondents noted that the use of cloud computing at work is advantageous $(\mathrm{M}=4.54, \mathrm{SD}=0.606)$. This means that cloud computing made the SMEs' processes more efficient. In so doing, it enhanced SMEs' productivity and performance and eventually led to profitability. As well, with cloud computing, the respondents only paid for what they used $(\mathrm{M}=4.1, \mathrm{SD}=$ 0.87).This conforms to the assertion by Feuerlicht and Govardhan [33] elucidating that cloud computing offers rented services on a pay-as-you-use basis which leads to adjusting the level of usage according to the current needs of the organization. They were also able to scale up their requirement when required $(\mathrm{M}=4.16$, $\mathrm{SD}=0.795$ ). Cloud computing therefore provides a wide array of benefits to SMEs with robust coordination features such that they can only pay for what they use and are able to scale up their requirements whenever needed. Consistently, Marston et al. [59] echo that with cloud computing, SMEs have almost instant access to hardware resources and a faster time to market with no upfront capital investment.

In addition, the respondents could access information any time from any place (M=4.29, $\mathrm{SD}=0.84)$. Most importantly, performance did not decrease with growing user base $(\mathrm{M}=3.83, \mathrm{SD}=0.961)$. There is thus better customer care and access to information reliably. Besides, the respondents could access and share resources placed on cloud $(\mathrm{M}=4.17, \mathrm{SD}=0.748)$.Individuals could access resources placed on cloud from any location hence saving on time and money. In tally with the above, Miller [60] infers that cloud computing can offer many advantages related to capacity, reliability, and flexibility. On the whole, the results on relative advantage summed up to a mean of 4.0541, standard deviation of 0.52369, skewness -1.519 and kurtosis 5.535. From the foregoing, the relative advantage of cloud computing are self-evident. The results were as shown in Table 2.

Table 2: Relative Advantage

\begin{tabular}{|l|c|c|c|c|}
\hline & M & SD & Kurtosis & Skewness \\
\hline Is advantageous & 4.54 & 0.606 & -1.442 & -0.32 \\
\hline We pay only for what I use. & 4.1 & 0.870 & 2.844 & -1.232 \\
\hline We are able to scale up our requirement when required. & 4.16 & 0.795 & -0.510 & 0.639 \\
\hline We can access information any time from any place. & 4.29 & 0.840 & -0.787 & -0.670 \\
\hline Performance does not de-crease with growing user base. & 3.83 & 0.961 & 0.891 & -2.393 \\
\hline we can access and share re-sources placed on cloud & 4.17 & 0.748 & -0.968 & 0.150 \\
\hline we need not maintain my IT infrastructure & 3.30 & 1.229 & -0.920 & 0.438 \\
\hline Composite Mean & $\mathbf{4 . 0 5 4 1}$ & $\mathbf{0 . 5 2 3 6 9}$ & $\mathbf{- 1 . 5 1 9}$ & $\mathbf{5 . 5 3 5}$ \\
\hline
\end{tabular}

Source: Field Data (2017)

Regarding compatibility, cloud computing was compatible with existing technological architecture of their company $(\mathrm{M}=3.89, \mathrm{SD}=0.835)$. The high compatibility of cloud computing with the technological architecture of the SMEs positively affected the adoption process. However, whenever there were incompatibility issues with cloud computing, there was use of integrated services $(\mathrm{M}=3.95, \mathrm{SD}=1.093)$. This means that SMEs have a backup in case of incompatibility issues. Additionally, the use of cloud computing at work was consistent with existing practices in their company $(\mathrm{M}=3.82, \mathrm{SD}=0.912)$. Customization was also easy in cloud-based services $(\mathrm{M}=3.87, \mathrm{SD}=0.916)$.It was also easy to import and export applications/data from cloud services $(\mathrm{M}=3.85, \mathrm{SD}=1.021)$. Further, the use of cloud computing at work was compatible with their firm's existing format, interface, and other structural data $(M=3.75, S D=0.998)$. This infers that the technical and procedural requirements of cloud computing are consistent with values and the technological requirements of the SMEs. However, in case of, non-customizable cloud-based services, the respondents incur retraining cost $(\mathrm{M}=3.54, \mathrm{SD}=1.053)$. Lastly, the respondents inferred that cloud computing is compatible with all aspects of their work $(M=4.03, \mathrm{SD}=0.868)$. The results on the compatibility of cloud computing summed up to a mean of 3.8381, standard deviation of 0.57663 , Skewness 0.051 and kurtosis -0.624 . Compatibility is therefore one of the significant aspects affecting the adoption of cloud computing among the selected SMEs in Nairobi County. The findings were as presented in Table 3 .

Table 3: Compatibility

\begin{tabular}{|c|c|c|c|c|}
\hline & $\mathbf{M}$ & SD & Kurtosis & Skewness \\
\hline $\begin{array}{l}\text { in case of any incompatibility issue, we ask cloud service provider to offer } \\
\text { integrated services }\end{array}$ & 3.95 & 1.093 & 2.624 & -0.915 \\
\hline are compatible with existing techno-logical architecture of my company & 3.89 & 0.835 & -1.067 & -0.3 \\
\hline Customization in cloud-based services is easy. & 3.87 & 0.916 & 0.228 & 0.839 \\
\hline Is consistent with existing practices in my company. & 3.82 & 0.912 & 0.653 & 0.857 \\
\hline $\begin{array}{l}\text { is compatible with my firm's existing format, interface, and other structural } \\
\text { data }\end{array}$ & 3.75 & 0.998 & 1.524 & -1.366 \\
\hline we incur re-training cost in case of non-customizable cloud-based services & 3.54 & 1.053 & 1.833 & 1.158 \\
\hline Is easy in importing and exporting applications/ data from cloud services. & 3.85 & 1.021 & 0.629 & -1.219 \\
\hline is compatible with all aspects of my work & 4.03 & 0.868 & -0.292 & 0.603 \\
\hline Composite Mean & 3.8381 & 0.57663 & $\mathbf{0 . 0 5 1}$ & -0.624 \\
\hline
\end{tabular}

Source: Field Data (2017) 
As far as complexity was concerned, through personal interaction with cloud computing, the respondents perceived it to be useful when it is easy to use $(\mathrm{M}=4.22, \mathrm{SD}=0.797)$. Besides, the respondents found cloud computing flexible to interact with $(\mathrm{M}=4.09, \mathrm{SD}=0.919)$. Moreover, performing many tasks together did not take up too much of their time $(\mathrm{M}=3.7, \mathrm{SD}=0.922)$. Additionally, the respondents found it easy to integrate their existing work with the cloud based services $(\mathrm{M}=3.68, \mathrm{SD}=1.125)$. Adoption was therefore perceived to be high since the respondents perceived the use of cloud computing to be useful, flexible to interact with and time saving. In conformity, prior scholars $[44,45]$ have espoused that new technologies have to be user-friendly and easy to use in order to increase the adoption rate

To sum up, the use of cloud computing did not expose the respondents to the vulnerability of computer breakdowns and loss of data $(\mathrm{M}=3.45, \mathrm{SD}=1.495)$. As such, the respondents were not prone to security and privacy issues. The results on the complexity of cloud computing summed up to a mean of 3.8298, standard deviation of 0.7131 , skewness -0.376 and Kurtosis of 0.048 as shown in Table 4.

Table 4: Complexity

\begin{tabular}{|c|c|c|c|c|}
\hline & $\mathbf{M}$ & SD & Kurtosis & Skewness \\
\hline Perceived to be useful when it is easy to use. & 4.22 & 0.797 & 0.918 & 0.169 \\
\hline Flexible to interact with. & 4.09 & 0.919 & 1.498 & -0.601 \\
\hline $\begin{array}{l}\text { Does not expose me to the vulnerability of computer breakdowns } \\
\text { and loss of data. }\end{array}$ & 3.45 & 1.495 & -0.671 & 0.475 \\
\hline $\begin{array}{l}\text { I find it easy to integrate my existing work with the cloud based } \\
\text { services. }\end{array}$ & 3.68 & 1.125 & -0.414 & 0.064 \\
\hline $\begin{array}{l}\text { Performing many tasks together does not take up too much of my } \\
\text { time. }\end{array}$ & 3.7 & 0.922 & 2.686 & 0.166 \\
\hline Composite Mean & 3.8298 & 0.7131 & -0.376 & 0.048 \\
\hline
\end{tabular}

Source: Field Data (2017)

\section{SaaS (Software as a Service)}

Software as a Service-computing model allows users to access simple desktop applications such as word processing and spreadsheets as a service on the web. From the findings, $23.3 \%$ (75) of the respondents use I-cloud computing in their business to a high extent, $24.2 \%$ (78) very high extent, $40.4 \%$ (130) moderate extent, $7.1 \%$ (23) low extent and 5\% (16) very low extent. The mean value of 3.55 was confirmation that I-cloud computing was used to a high extent in their business while the standard deviation of 1.085 further revealed high degree of variation in the responses.

In a bid to establish the extent to which the respondents apply email service in their business, the respondents were asked to respond accordingly. 30.7\% (99) of the respondents noted that they apply email service in their business to a high extent, $40.1 \%$ (129) very high extent, $22 \%$ (71) moderate extent, 5.3\% (17) low extent and $1.9 \%$ (6) very low extent. The item realized a mean of 4.02 and standard deviation of 1.001 meaning that the respondents are able to apply email in their business to a high extent.

To establish whether the extent to which the email application service is accessible from anywhere anytime, respondents were requested for their opinion and the results were such that, $43.5 \%$ (140) of the respondents noted that the email application is accessible from anywhere anytime to a high extent, $18.6 \%$ (60) to a very high extent, $28.9 \%$ (93) moderate extent, $8.1 \%$ (26) low extent and $0.9 \%$ (3) very low extent. The results summed up to a mean of 3.71 and standard deviation of 0.894 an indication that the email application is accessible anywhere anytime. It is therefore convenient for the SMEs since they can effectively interact with their customer base.

In order to ascertain the extent to which CRM services have been adopted, the respondents were asked to respond accordingly. The results revealed that, $43.5 \%$ (140) of the respondents noted that CRM services have been adopted to a high extent, $18.6 \%$ (60) very high extent, $28.9 \%$ (93) moderate extent and $8.1 \%$ (26) low extent. This summed up to a mean of 3.41 and standard deviation of 1.073. From the foregoing, CRM users can access applications on demand.

In order to find out to what extent the respondents think their firm's CRM services are effective, the respondents were asked for their views on this and the results showed that $36 \%$ (116) of the respondents find CRM services to be effective to a high extent, $25.2 \%$ (81) to a very high extent, $34.2 \%$ (110) moderate extent and $4.7 \%$ (15) low extent The item realized a mean of 3.82 and a standard deviation of 0.865 an indication that the CRM services are effective. Besides, the standard deviation is indicative of fewer variations in the responses. The results findings are indicated in Table 5. 
Table 5: SaaS (Software as a Service)

\begin{tabular}{|c|c|c|c|c|}
\hline Item & M & SD & Skewness & Kurtosis \\
\hline $\begin{array}{l}\text { To what extent do you use I-cloud computing in your } \\
\text { business }\end{array}$ & 3.55 & 1.085 & -1 & 0.08 \\
\hline To what extent do you apply email service in your business & 4.02 & 1.001 & -1 & 0.06 \\
\hline $\begin{array}{l}\text { To what extent is your email application service accessible } \\
\text { from anywhere anytime }\end{array}$ & 3.71 & 0.894 & -0.4 & -1.5 \\
\hline To what extent have you adopted CRM services? & 3.41 & 1.073 & -0.5 & -1 \\
\hline $\begin{array}{l}\text { To what extent do you think your firm's CRM services are } \\
\text { effective? }\end{array}$ & 3.82 & 0.865 & -0.3 & -1.3 \\
\hline $\begin{array}{l}\text { To what extent do you think your firm's CRM services are } \\
\text { efficient? }\end{array}$ & 3.67 & 1.03 & -0.4 & -1.6 \\
\hline Composite mean for SaaS & 3.6957 & 0.73143 & -0.768 & 0.397 \\
\hline
\end{tabular}

Source: Field Data (2017)

\section{PaaS (Platform as a Service)}

In regards to the extent, the respondents utilized cloud data storage service. Of the total respondents, $25.8 \%$ noted that cloud data storage service was utilized to a high extent, $29.2 \%$ (94) very high extent, $29.2 \%$ (94) moderate extent, $12.4 \%$ (40) low extent and 3.4\% (11) very low extent. The results summed up to a mean of 3.65 and standard deviation of 1.126. The results implied that the SMEs have utilized cloud data storage services.

The study further enquired from the respondents the extent to which cloud data storage service is effective. The results revealed that $39.4 \%$ (127) of the respondents found cloud data storage service to be effective to a high extent, $19.9 \%$ (64) very high extent, $27.6 \%$ (89) moderate extent, $8.4 \%$ (27) low extent and $4.7 \%$ (15) very low extent. The results summed up to a mean of 3.61 and standard deviation of 1.042. On the whole, the respondents found the cloud data storage services effective.

Further, respondents were also asked the extent to which their firm was enjoying server and network service maintenance offered by their service providers. The results showed that $40.7 \%$ (131) of the respondents enjoyed server and network service maintenance offered by their service providers to a high extent, $10.2 \%$ (33) very high extent, $43.8 \%$ (141) moderate extent, $3.1 \%$ (10) low extent and $2.2 \%$ (7) very low extent. The results summed up to a mean of 3.54 and standard deviation of 0.805 meaning a significant number of the SMEs were enjoying server and network service maintenance offered by their service providers. Besides, the standard deviation indicates less variation in the responses.

The respondents were also asked the amount of data they store in the I-cloud. The results indicated that $42.9 \%$ (138) of the respondents stored data in the I-cloud to a high extent, $8.7 \%$ (28) very high extent, $41.3 \%$ (133) moderate extent, $5.9 \%$ (19) low extent and 1.2\% (4) very low extent. The item realized a mean of 3.52 and standard deviation of 0.786 . Generally, the results on Platform as a Service summed up to a mean of 3.58 , standard deviation of 0.79549 , Skewness -0.697 and Kurtosis 0.384 . This infers that most of the respondents were agreeable and there is less variation in the responses. Additionally, the skewness and kurtosis values ranged from -1.96 to +1.96 hence there was normal distribution of the responses as illustrated in Table 6 .

Table 6: PaaS (Platform as a Service)

\begin{tabular}{|l|c|c|c|c|}
\hline Item & M & SD & Skewness & Kurtosis \\
\hline To what extent do you utilize cloud data storage service & 3.65 & 1.126 & -0.7 & -0.8 \\
\hline To what extent is your cloud data storage service effective & 3.61 & 1.042 & -0.6 & 1.78 \\
\hline $\begin{array}{l}\text { To what extent is your firm enjoying server and network service } \\
\text { maintenance offered by your service providers }\end{array}$ & 3.54 & 0.805 & -0.3 & -1.3 \\
\hline What amount of data do you store in the cloud & 3.52 & 0.786 & 0.12 & -1.4 \\
\hline Composite Mean for PaaS & $\mathbf{3 . 5 8}$ & $\mathbf{0 . 7 9 5 4 9}$ & $\mathbf{0 . 3 9}$ & $\mathbf{- 1 . 5}$ \\
\hline
\end{tabular}

Source: Field Data (2017)

\section{IaaS (Infrastructure as a Service)}

The basic strategy of IaaS is to set up a fixable environment where consumers are allowed to perform several activities on the server, for instance, starting and stopping it, customizing it by installing software packages, attaching virtual disks to it, and configuring access permissions and firewall rules [38]. The respondents were asked the extent to which the cloud infrastructure is reliable. The results from the study revealed that, of the total respondents, $32.3 \%$ (104) found the cloud infrastructure to be reliable to a high extent, $22.4 \%$ (72) very high extent, 30.4\% (98) moderate extent, $6.5 \%$ (21) low extent and $8.4 \%$ (27) very low extent. The mean value was 3.54 and standard deviation 1.155 implying that the cloud infrastructure was reliable hence can be used SMEs to meet their goals.

In determining the extent to which the respondents think of server upgrades, the study revealed that; $33.2 \%$ (107) of the respondents thought of server upgrades to a high extent, $15.5 \%$ (50) very high extent, $35.4 \%$ 
(114) moderate extent, $14.6 \%$ (47) low extent and $1.2 \%$ (4) very low extent. The results summed up to a mean of 3.47 and standard deviation of 0.964 .

Regarding the extent to which the respondents enjoy server upgrades by their cloud service provider, $38.8 \%$ (125) of them enjoyed server upgrades to a high extent, $10.6 \%$ (34) very high extent, $44.7 \%$ (144) moderate extent, $4.7 \%$ (15) low extent and $1.2 \%$ (4) very low extent. The results summed up to a mean of 3.53 and standard deviation of 0.794 inferring that the respondents enjoyed server upgrades by their cloud service. The standard deviation indicated less variation in the responses.

In determining the extent to which the respondents feel their infrastructure is the responsibility of the cloud service provider, the study revealed that; $41.6 \%$ (134) of the respondents felt to a high extent that their infrastructure is the responsibility of the cloud service provider, 26.4\% (85) to a very high extent, 29.2\% (94) moderate extent, $1.6 \%$ (5) low extent and $1.2 \%$ (4) very low extent. The results summed up to a mean of 4.01 and standard deviation of 2.186. Table 7 illustrates the findings of the study.

Table 7: IaaS (Infrastructure as a Service)

\begin{tabular}{|c|c|c|c|c|}
\hline Item & $\mathbf{M}$ & SD & Skewness & Kurtosis \\
\hline How reliable is your cloud infrastructure & 3.54 & 1.155 & -12 & 137 \\
\hline To what extent do you often think of server upgrades & 3.47 & 0.964 & -2.3 & 7.33 \\
\hline $\begin{array}{l}\text { To what extent do you enjoy server upgrades by your cloud service } \\
\text { provider }\end{array}$ & 3.53 & 0.794 & -1.5 & 3.63 \\
\hline $\begin{array}{l}\text { To what extent do you feel your infrastructure is the responsibility } \\
\text { of the cloud service provider that }\end{array}$ & 4.01 & 2.186 & 0.67 & -0.6 \\
\hline Composite Mean for IaaS & 3.64 & 0.806 & 1.958 & 2.409 \\
\hline
\end{tabular}

Source: Field Data (2017)

\section{Component and Regression Analysis}

The researchers ran a principal component analysis to identify patterns in data, and to express the data in such a way as to highlight their similarities and differences. Besides having data set items reduced to manageable level while retaining as much of the original information, it helped in identifying groups or clusters of variables. By use of varimax rotation, the researchers retained all factors with Eigen values greater than 1. The criterion was based on the idea that the Eigen values represent the amount of variation explained by a factor and that the Eigen value of 1 represents a substantial amount of variation. Sampling adequacy was tested using the Kaiser- Meyer-Olkin Measure (KMO measure) of sampling adequacy. As evidenced in Table 8, KMO was greater than 0.5. The KMO Measure is an index for comparing the magnitude of the observed correlation coefficients to the magnitude of the partial correlation coefficients.

Table 8: Factor Analysis

\begin{tabular}{|c|c|c|c|c|c|c|}
\hline & \multicolumn{3}{|c|}{ Total Variance Explained } & \multirow[b]{2}{*}{ KMO } & \multirow[b]{2}{*}{$\begin{array}{l}\text { Bartlett's Test } \\
\text { Chi-Square }\end{array}$} & \multirow[b]{2}{*}{ Sig. } \\
\hline & Total & $\begin{array}{l}\text { \% of } \\
\text { Variance }\end{array}$ & $\begin{array}{l}\text { Cumulative } \\
\%\end{array}$ & & & \\
\hline \multirow[t]{3}{*}{ Relative advantage } & 1.997 & 28.54 & 28.54 & 0.662 & 518.8 & 0 \\
\hline & 1.845 & 26.36 & 54.89 & & & \\
\hline & 1.139 & 16.27 & 71.17 & & & 0 \\
\hline \multirow[t]{2}{*}{ Compatibility } & 2.539 & 31.74 & 30.36 & 0.693 & 669.6 & 0 \\
\hline & 1.923 & 24.037 & 55.77 & & & \\
\hline \multirow[t]{2}{*}{ Complexity } & 2.111 & 42.22 & 42.22 & 0.635 & 342.3 & 0 \\
\hline & 1.308 & 26.16 & 68.38 & & & \\
\hline \multirow[t]{2}{*}{ SaaS } & 2.958 & 49.31 & 49.31 & 0.798 & 968.9 & 0 \\
\hline & 1.443 & 24.04 & 73.35 & & & \\
\hline \multirow[t]{2}{*}{$\mathrm{PaaS}$} & 2.058 & 51.46 & 51.46 & 0.813 & 605.8 & 0 \\
\hline & 1.301 & 32.52 & 83.98 & & & \\
\hline \multirow[t]{2}{*}{ IaaS } & 1.795 & 44.87 & 44.87 & 0.461 & 242.3 & 0 \\
\hline & 1.055 & 26.38 & 71.24 & & & \\
\hline
\end{tabular}

To examine the relationship between technology context and cloud computing adoption, a null hypothesis that stated that "there is no significant relationship between technology context and cloud computing adoption" was formulated. After running multiple regression analysis, the results indicated a significant and positive relationship between technology context and with cloud computing adoption. As shown in Table 9, technology context exhibited a positive and significant effect on level of adoption of cloud computing 0.414 , $\rho<0.05)$. Consequently, the null hypothesis was rejected and the alternative accepted. This indicates that there is a change of cloud computing adoption by 0.414 units with an increase in the technology context. 
Effects of Technology Context on Cloud Computing Adoption in Small and Medium Enterprises in

Table 9: Regression Coefficients

\begin{tabular}{|l|c|c|c|c|c|c|c|c|}
\hline & \multicolumn{2}{|c|}{$\begin{array}{c}\text { Unstandardized } \\
\text { Coefficients }\end{array}$} & \multicolumn{2}{c|}{ Standardized Coefficients } & Correlations & \multicolumn{2}{c|}{$\begin{array}{c}\text { Collinearity } \\
\text { Statistics }\end{array}$} \\
\hline & $\mathbf{B}$ & $\begin{array}{c}\text { Std. } \\
\text { Error }\end{array}$ & $\boldsymbol{\beta}$ & $\mathbf{t}$ & $\mathbf{S i g}$ & Zero-order & Tolerance & VIF \\
\hline (Constant) & 0.604 & 0.224 & & 2.692 & 0.007 & & & \\
\hline Technology context & 0.513 & 0.07 & 0.414 & 7.349 & 0.000 & 0.576 & 0.572 & 1.748 \\
\hline
\end{tabular}

Dependent Variable: Cloud Computing Adoption

Source: Field Data (2017)

\section{Discussion}

Based on the above observations, the findings validate the conceptual framework developed in this work as they shed light on the link between technological context and adoption of cloud computing among SMEs. These findings also provide support for the assertion that technology with a relative advantage, compatible with existing technology, and not complex to use has an effect on cloud computing adoption. It is, therefore, important to note that for SMEs to adopt any technology, it must be easy to use and have a relative advantage. It should also be a technology that benefits the small businesses and must be compatible with the already existing technology that businesses are already using. The technology should be one which can easily be integrated with the existing one.

Cloud computing provides a service that shares resources offering SMEs the advantage of being able to access resources placed on cloud from any location and thus it saves businesses time and money. The findings also intimate that cloud computing promises a variety of gains to companies. Entrepreneurs are aware of the benefits of cloud computing such as access of information from any point and at any time, and sharing of resources placed on the cloud. Overall, cloud computing provides SMEs with more control over their operations. Furthermore, adopting cloud computing is likely to add relative advantage to the firm by lowering the cost of entry for SMEs to access a vast pool of computing resources for relatively short amount of time.

It is also evident, based on study findings, that when SMEs perceive that an innovation offers a relative advantage, then it is more likely that they will adopt that innovation. In addition, whenever cloud computing is recognized as compatible with the work application system, there is a higher likelihood of adoption of the technology by SMEs. In the event that it is incompatible, cloud service providers' offer integrated services. Regarding complexity, it suffices to argue that there is a significant nexus between complexity and the adoption of cloud computing. This is because when innovation become less challenging to use, it is likely to be adopted. Adopting a new technology may confront SMEs with challenges in terms of changing the processes in which they interact with their business systems. New technologies have to be user-friendly and easy to use in order to increase the adoption rate.

\section{Conclusion And Recommendations}

This paper has demonstrated that technology context, and its attendant aspects (relative advantage, compatibility and complexity), significantly influence cloud computing. Specifically, relative advantage as a component of the technology context affects the level of adoption of cloud computing among SMEs. Moreover, compatibility is an essential component of cloud computing adoption and SMEs will be more likely to adopt if cloud computing is compatible with the existing systems in the organization. Additionally, in order to enhance the adoption of cloud computing, SMEs require new skills and expertise to manage cloud solutions.

From the foregoing conclusion, the paper calls for the need for SMEs to perceive cloud computing as a new computing model that could increase their profitability before they take a positive adoption decision. Furthermore, in order to enhance the adoption of cloud computing, it is important for SMEs to ensure that cloud services are compatible with the organization's systems. Also, there is need for the cloud computing services to be compatible with statutory regulation. In addition, there is need for the technical and procedural requirements of the innovation to be compatible and consistent with values and the technological requirements of the adopting organization. Consequently, it is essential for SMEs that the new innovation is consistent with their existing values and needs.

\section{References}

[1] Sogorb-Mira, F. (2005). How SME Uniqueness Affects Capital Structure: Evidence from a 1994-1998 Spanish Panel Data. Small Business Economics, 25, 447-457.

[2] Wagenvoort, R. (2003). SME Finance in Europe: Introduction and Overview. European Investment Bank Papers, 8(2), 10-21.

[3] Ongori, H. (2009). Role of Information Communication Technologies Adoption in SMES: Evidence from Botswana. Research Journal of Information Technology, 1(2), 79-85.

[4] Pauly, M. (2011). T-Systems Cloud-Based Solutions for Business Applications. In R. Buyya, J. Broberg and A. Goscinski (Eds.), Cloud Computing: Principles and Paradigms. Hoboken, NJ: John Wiley \& Sons, Inc.

[5] Swash, G. (1998). UK Business Information on the Internet. New Library World, 99(1144), 238-242. 
[6] Bayo-Moriones, A., \& Lera-Lo'pez, F. (2007). A Firm-Level Analysis of Determinants of ICT Adoption in Spain. Technovation, 27(6-7), 352-366.

[7] Hartigan, P. (2005). El emprendedor social como modelo para el futuro. Iniciativa Emprendedora Y Empresa Familiar, 46, $19-25$.

[8] European Commission. (2005). The New SME Definition: User Guide and Model Declaration. Luxembourg: Office for Official Publications of the European Communities.

[9] Njama, G. J. (2013). Effects of Venture Capital Financing on the Growth of Small and Medium Enterprises in Kenya. Unpublished MBA Thesis, University of Nairobi.

[10] Ebiringa, O. T. (2011). Synthesis of Literature on Small and Medium Enterprises Start-Up Financing. Int. J. Eco. Res., 2(1), 85-95.

[11] Ibrahim, O. A., \& Musah, A. (2015). Small and Medium Enterprises in the Cloud in Developing Countries: A Synthesis of Literature and Future Research Directions. Journal of Management and Sustainability, 5(1), 115-139.

[12] Ishan, R. S. (2016). Cloud Computing Adoption in Australia. Unpublished PhD Thesis, Deakin University.

[13] Gartner (2009). Cloud Computing Inquiries at Gartner. Available at: http://blogs.gartner.com thomas_bittman/2009/10/29/cloudcomputing-inquiries at-gartner (accessed 16 September 2016).

[14] Erdogmus, H. (2009). Cloud Computing: Does Nirvana Hide Behind the Nebula? IEEE Software, 26, 4-6.

[15] Sultan, N. (2010). Cloud Computing for Education: A New Dawn? International Journal of Information Management, 30, 109-116.

[16] Goscinski, A., \& Brock, M. (2010). Toward Dynamic and Attribute Based Publication, Discovery and Selection for Cloud Computing. Future Generation Computer Systems, 26, 947-970.

[17] Mutula, S. M. \& Brakel P. V. (2006). E-readiness of SMEs in the ICT Sector in Botswana with Respect to information. The Electronic Library, 24(3), 402-417.

[18] Chatman, C. (2010). How Cloud Computing is Changing the Face of Health Care Information Technology. Journal of Health Care Compliance, 12(3), 37-70.

[19] Kuo, A. M. H. (2011). Opportunities and Challenges of Cloud Computing to Improve Health Care Services. Journal of Medical Internet Research, 13(3), e67.

[20] Japan-NE. (2012). Fujitsu Roll Out Cloud Computing Services for Hospitals. Telecom paper Africa/Asia. Available from http://www.accessmylibrary.com/article

[21] Lisa, B. A. (2011). Hospital Uses Cloud Computing to Improve Patient Care and Reduce Costs. Available: http://www.microsofteu/cloudcomputing/casestudies/hospitalusescloudcomputingtoimprovepatientcareandreducecosts.aspx . Accessed 20 Feb 2017

[22] Tornatzky, L. G., \& Fleischer, M. (1990). The Processes of Technological Innovation. Lexington, MA: Lexington Books.

[23] Chau, P. Y. K., \& Tam, K. Y. (1997). Factors Affecting the Adoption of Open Systems: An Exploratory Study. MIS Quarterly, 21, $1-24$.

[24] Chong, A. Y. L., \& Ooi, K. B. (2008). Adoption of Interorganizational System Standards in Supply Chains: An Empirical Analysis of Rosettanet Standards. Industrial Management \& Data Systems, 198, 529-547.

[25] Zhu, K., Kraemer, K. L., Xu, S., \& Dedrick, J. (2004). Information Technology Payoff in E-Business Environments: An International Perspective on Value Creation of E-business in the Financial Services Industry. Journal of Management Information Systems, 21, 17-54

[26] Rui, G. (2007), Information Systems Innovation Adoption among Organizations a MatchBased Framework and Empirical Studies, National University of Singapore, Singapore.

[27] Oliveira, T., \& Martins, M. (2011). Literature Review of Information Technology Adoption Models at Firm Level. The Electronic Journal Information Systems Evaluation, 14(1), 110-121.

[28] Baker, J. (2011). The Technology-Organization-Environment Framework. In Dwivedi, Y., Wade, M., \& Schneberger, S. (Eds.), Information Systems Theory: Explaining and Predicting Our Digital Society (231-246). New York: Springer.

[29] Rogers, E. (2003). Diffusion of Innovations ( $5^{\text {th }}$ Ed.). New York: Free Press.

[30] Rogers, E. (1983). Diffusion of Innovations. New York: Free Press.

[31] To, M. L., \& Ngai, E. W. T. (2006). Predicting the Organizational Adoption of B2C e-Commerce: An Empirical Study. Industrial Management \& Data Systems, 106, 1133-47.

[32] Armbrust, M., Fox, A., Griffith, R., Joseph, A. D., Katz, R., Konwinski, A., Lee, G., Patterson, D., Rabkin, A., Stoica, I., \& Zaharia, M. (2010). A View of Cloud Computing. Communications of the ACM, 53, 50-58

[33] Feuerlicht, G., \& Govardhan, S. (2010). Impact of Cloud Computing: Beyond a Technology Trend. In the Proceedings of the International Conference on Systems Integration 2010 [CDROM]. 8-9 June, 2010, Prague, Oeconomica, 1-8.

[34] Thong, J., Yap, C., \& Raman, K. (1994). Engagement of External Expertise in Information Systems Implementation. Journal of Management Information Systems, 11(2), 209-231.

[35] Thong, J. (1999). An Integrated Model of Information Systems Adoption in Small Businesses. Journal of Management Information Systems, 15(4), 187-214.

[36] Lee, J. (2004). Discriminant Analysis of Technology Adoption Behaviour: A Case of Internet Technologies in Small Businesses. Journal of Computer Information Systems, 44(4), 57-66.

[37] Sokolov, I. P. (2009). Cloud Computing: Overview, Concepts and Business Deployment Scenarios. Vienna: Vienna University of Economics and Business.

[38] Buyya, R., Yeo, C. S., Venugopa, S., Broberg, J., \& Brandic, I. (2009). Cloud Computing and Emerging IT Platforms: Vision, Hype, and Reality for Delivering Computing as the 5th Utility. Future Generation Computer Systems, 25, $599-616$.

[39] Premkumar, G., Ramamurthy, K., \& Sree, N. (1994). Implementation of Electronic Data Interchange: An Innovation Diffusion Perspective. Journal of Management Information Systems, 11, 157-186.

[40] Wang, Y. M., Wang, Y. S., \& Yang, Y. F. (2010). Understanding the Determinants of RFID Adoption in the Manufacturing Industry. Technological Forecasting \& Social Change, 77, 803-815.

[41] Akbulut, A. A. (2003). An Investigation of the Factors that Influence Electronic Information Sharing between State and Local Agencies. Unpublished Doctoral Dissertation, Louisiana State University.

[42] Chau, Y. K., \& Hu, J. H. (2001). Information Technology Acceptance by Individual Professionals: A Model Comparison Approach. Decision Sciences, 32(4), 669-719.

[43] Hardgrave, B., Davis, F., \& Riemenschneider, C. (2003). Investigating Determinants of Software Developers' Intentions to Follow Methodologies. Journal of Management Information Systems, 20(1), 123-151.

[44] Parisot, A. (1995). Technology and Teaching: The Adoption and Diffusion of Technological Innovations by a Community College Faculty. Bo-zeman, MT: Montana State University.

[45] Sahin, I. (2006). Detailed Review of Rogers' Diffusion of Innovations Theory and Educational Technology-Related Studies Based on Rogers' Theory. The Turkish Online Journal of Educational Technology, 5(2), 14-23. 
[46] Jain, L., \& Bhardwaj, S. (2010). Enterprise Cloud Computing: Key Considerations for Adoption. International Journal of Engineering and Information Technology, 2(2), 113-117.

[47] Tan, S. K., Chong, S. C., Lin, B., \& Eze, U. C. (2008). Internet-based ICT Adoption: Evidence from Malaysian SMEs. Industrial Management \& Data Systems, 109, 224-244.

[48] Oliveira, T., \& Martins, M. F. (2010). Understanding e-Business adoption Across Industries in European Countries. Industrial Management \& Data Systems, 110, 1337-54.

[49] Lin, H. F., \& Lin, S. M. (2008). Determinants of e-Business Diffusion: a Test of the Technology Diffusion Perspective. Technovation, 28, 135-145.

[50] Makena, J. N. (2013). Factors that Affect Cloud Computing Adoption by Small and Medium Enterprises in Kenya. International Journal of Computer Applications Technology and Research, 2(5), 517.

[51] Kituku, K.M. (2012). Adoption of Cloud Computing in Kenya by Firms Listed in the Nairobi Stock Exchange. Unpublished MBA Thesis, University of Nairobi.

[52] Osterman, M. D. (2012). Digital Literacy: Definition, Theoretical Framework, and Competencies. In M. S. Plakhotnik, S. M. Nielsen, \& D. M. Pane (Eds.), Proceedings of the 11th Annual College of Education \& GSN Research Conference (pp. 135-141). Miami: Florida International University.

[53] Rogers, E. (1995). Diffusion of Innovations ( $4^{\text {th }}$ Ed.). New York: Free Press.

[54] Agarwal, R., Sambamurthy, V., \& Stair, R. M. (2000). The Evolving Relationship between General and Specific Computer Efficacy: An Empirical Assessment. Information Systems Research, 11(4), 418-430.

[55] Pedersen, S., \& Liu, M. (2003). Teachers' Beliefs about Issues in the Implementation of a Student-Centred Learning Environment. Educational Technology Research and Development, 51(2), 57-76.

[56] Nairobi County, 2015. Ministry of Trade Records

[57] Yates, D., Moore, D., \& Starnes, D. (2008). The Practice of Statistics ( ${ }^{\text {rd }}$ Ed.). New York: W. H. Freeman and Company.

[58] Gardner, C., \& Amoroso, D. L. (2004). Development of an Instrument to Measure the Acceptance of Internet Technology by Consumers. Proceeding of the 37th Hawaii International Conference of System Science, IEEE, 1-10.

[59] Marston, S., Li, Z., Bandyopadhyay, S., Zhang, J., \& Ghalsasi, A. (2011). Cloud Computing - The Business Perspective. Decision Support Systems, 51(1), 176-189.

[60] Miller, M. (2008). Cloud Computing: Web-Based Applications That Change the Way You Work and Collaborate Online. Indiana, IN: Que. 